\title{
ESTUDIO DE LA DINÁMICA DE LA TRANSMISIÓN ORAL
}

\section{STUDY OF ORAL TRANSMISSION DYNAMIC}

\author{
Martha Esquenazi Pérez*
}

\begin{abstract}
RESUMEN
En este artículo se propone una metodología para el estudio de la dinámica de la transmisión oral de géneros musicales, tomando en consideración las edades de los practicantes, si estos transmiten a otros sus conocimientos y si la práctica de los géneros se realiza preferentemente en zonas urbanas o rurales. Los resultados se presentan cartográficamente. La aplicación de este método ayuda a precisar si los géneros estudiados tienen o no posibilidades de continuar existiendo en la práctica cultural de la población.
\end{abstract}

PALABRAS CLAVE: CUBA * TRADICIÓN ORAL * METODOLOGÍA * DINÁMICA CULTURAL * MÚSICA

\section{ABSTRACT}

In this article, we proposed a methodology in order to study the oral transmission dynamic of music, taking into account the ages of those who practice it, if they transmit their knowledge to others and if the practice of genders is mainly practiced in urban or rural areas. The results of these studies are presented in maps. The application of this method helps us to determinate if the studied genders have real possibilities of going on or not in the people cultural practice.

KEYWORDS: CUBA * ORAL TRADITION * METHODOLOGY * CULTURAL DYNAMICS * MUSIC 


\section{INTRODUCCIÓN}

La transmisión de los géneros de la música de tradición oral funciona básicamente, en el seno de los núcleos familiares y se proyecta en las comunidades, este mecanismo les permite subsistir a través de varias generaciones, pasándose los conocimientos de padres a hijos y además, proyectarse como práctica social en su medio, sea rural o urbano.

Este mecanismo en constante movimiento permite que las tradiciones orales posean rasgos de gran antigüedad, las cuales se conservan a través de siglos por esta práctica continua de la transmisión y a su vez, se van introduciendo pequeños cambios de forma natural en el propio sitio con permutas internas que pueden ir desde la asimilación de rasgos de otros géneros, el cambio de un género cuyo origen podría ser religioso y pasa a ser laico o a la inversa, introducción de nuevas técnicas de interpretación o de nuevos contenidos temáticos por influencia de otros géneros afines o con el traslado de los practicantes hacia otros sitios, produciéndose una expansión geográfica de la tradición, en muchas ocasiones se producen cambios e innovaciones en estos traslados, ya que generalmente, cada región posee rasgos propios que se van incorporando al nuevo género acogido haciéndolo suyo, sin que cambie la esencia del género que se trasmite en cuanto a la estructura interna de la manifestación, permitiendo identificar su filiación genérica.

Este concepto se puede comprender mejor si se aplica a algún género en específico, a modo de ejemplo se utilizará un género bastante conocido en Latinoamérica: la décima cantada. La décima octosílaba cantada de origen hispánico pasó a ser cultivada en los países colonizados por los españoles y portugueses como: Argentina, Chile, Brasil, Uruguay, Venezuela, México, Panamá, Puerto Rico, Santo Domingo, Perú, Ecuador, Bolivia, Colombia y Cuba (Esquenazi, 2008: 64). Cada país en que se practica este género, le ha incorporado rasgos propios como la forma de emisión de la voz que generalmente, va de la emisión nasal a otras formas más específicas asociadas a los grupos étnicos que la practican, el acompañamiento instrumental también varía, por ejemplo, en algunas regiones se ha perdido el acompañamiento instrumental y se recitan las décimas, en otras los estilos de interpretación varían como la sustitución del acompañamiento instrumental de cifra por el de la milonga en Argentina y Uruguay (Moreno, 2000: 294) aunque siempre se pueden identificar dos estilos básicos: uno que se puede denominar libre y que es heterofónico, en el cual prima la melodía interpretada por el cantante mientras se subordinan las cuerdas y otro que se puede denominar como fijo, el cual posee un ritmo en el acompañamiento armónico de las cuerdas, esta última forma posee variantes o estilos que van desde el uso de varias voces hasta los cambios de acentuación en el ritmo, dando lugar a un sinnúmero de modalidades interpretativas; no obstante, conservan el uso de fórmulas melódicas para la interpretación de las décimas octosílabas y las escalas empleadas son modales, rasgos que indican la antigüedad del género.

\section{1) NECESIDAD DE PRECISAR LAS POSIBILIDADES DE CONTINUACIÓN DE LAS TRADICIONES}

Cuando un investigador se enfrenta al estudio de cualquier género de la tradición oral, tiende a valorar la vigencia y posible perdurabilidad del mismo, basándose en la observación que hace en el lugar donde ha investigado $y$ tiende a hacer extensiva esta valoración a la región y en ocasiones, hasta en el país en general. Es frecuente leer en algunas monografías este tipo de apreciaciones que afirman que determinado género o manifestación cultural están condenados a la desaparición y muchos años después, al volver al sitio, otros investigadores constatan la existencia de la manifestación en cuestión, no solo en la región sino incluso en el país.

Esto planteó la necesidad de encontrar un método que pudiera medir con mayor imparcialidad el proceso dinámico de las tradiciones orales, con este objetivo, se introdujeron varias preguntas en los cuestionarios sobre música tradicional cubana durante la investigación del Atlas etnográfico de Cuba. Básicamente, se preguntaba la edad del informante $y$ si sus hijos u otras personas aprendían de él a 
practicar el género sobre el que informaba.

Se establecieron tres grupos de edades con un rango de 30 años como límite entre ellos, esta cantidad de años se adoptó por coincidir con la de una generación y usualmente, se emplea para medir el mantenimiento de una tradición oral (aunque algunos estudiosos utilizan 25 años como límite de tiempo). Los grupos de edades determinados para los informantes entrevistados fueron los siguientes: de 1 a 30 años, de 31 años a 60 y más de 61 años.

La información se tomó básicamente, durante la década de los ochenta, por lo que mantiene su vigencia hasta la década actual.

El siguiente rasgo a tomar en cuenta fue si la transmisión del género de generación en generación se estaba efectuando o no, si se realizaba se le denomina como transmisión positiva y sino, como negativa.

Otro dato importante debido a lo controversial es si el género se desarrolla en áreas rurales o urbanas, siendo algo que también cae generalmente, en el ámbito de las observaciones personales $y$ por tanto, subjetivas. Muchos géneros que se desarrollaban en áreas rurales han ido pasando paulatinamente a las áreas urbanas con el traslado de sus cultores, esto trae por consecuencia una ambivalencia que se manifiesta con la práctica de los géneros estudiados en ambos tipos de poblaciones, por lo cual se solucionó seleccionando la categoría de acuerdo al predominio numérico de una de las dos variantes en las áreas estudiadas.

Es importante añadir a toda esta información tomada del trabajo de campo, otros datos que aparecen en fuentes bibliográficas variadas como: libros de texto, archivos históricos, periódicos y revistas — tanto nacionales como locales- de diversos períodos históricos. Este rastreo permite establecer la antigüedad histórica del género, en algunas ocasiones se encuentran referencias sobre la práctica de un género en una región donde ya no se practica $y$ otras veces, se puede establecer una comparación entre la forma en que se realizaba en otra época y la actual.

Cuando se tiene una información de tipo general que abarca varias localidades, la forma más apropiada de plasmarla es por medio de la cartográfica, aunque no se excluye el uso de gráficos diversos cuando se trate de una manifestación cultural muy específica o perteneciente a un solo sitio.

\section{2) BREVE RESEÑA SOBRE LAS MANIFESTACIONES MUSICALES ESCOGIDAS PARA LA APLICACIÓN DEL MÉTODO PROPUESTO}

Para ejemplificar la propuesta metodológica, se escogieron tres manifestaciones musicales: como representación de la música de antecedente hispánico se escogió el punto guajiro o cubano, como símbolo de la música de antecedente africano se escogió la conga o bantú y como distintiva de la música aportada por inmigrantes durante el siglo xx, se escogió la de los haitianos que corresponden a esta época histórica.

Los mapas publicados en el cD Atlas etnográfico de Cuba correspondientes a estos temas, se reproducen, a manera de complemento de la información. En estos mapas, la información se encuentra detallada a nivel de municipio, de esta forma se puede conocer que lugares son exactamente en los que se practican estos géneros. En el caso del punto guajiro, se señalan los pocos municipios donde el género se dejó de practicar (por tanto, tiene carácter no vigente o histórico) y aquellos donde no se obtuvo información sobre el tema. Por la masividad de la expresión en la práctica de los estilos musicales de este género (libre, fijo, cruzado, espirituano, parranda y seguidilla), se analizó a nivel provincial, plasmándose la incidencia de los mismos a través de los cartodiagramas.

Asimismo, se realizó un desglose de los instrumentos empleados en los conjuntos campesinos y cuales eran más o menos utilizados en los mismos, con diferentes combinaciones instrumentales. En el Atlas de los instrumentos musicales realizado por el Centro de Investigaciones y Desarrollo de la Música Cubana (сірмuc), se llegaron a identificar veintitrés combinaciones instrumentales en el mapa de conjuntos de punto (Eli, 1996: 46).

Este género se practicó en Portugal desde el siglo xiv (López, 2002: 29) y en España desde el xv. En el siglo xvI, Vicente Espinel introdujo 
una forma de décima a la que llamó redondilla, publicó diez en total: dos en el Poema trágico del español Gerardo (1815) y ocho en el libro Diversas rimas (1591). Este tipo de décima fue nombrada por Lope de Vega como Espinela y fue utilizada por él y otros poetas contemporáneos hasta popularizarse y llegar a ser el tipo de décima que se cultiva preferentemente en América Latina (Trapero, 2000: 122-124).

En Cuba se denominó como Ay el Ay, Ey y el Llanto en el siglo xix, también se mencionó el punto de harpa (sic), el zapateo y el atajaprimo; estas últimas como géneros donde se cantaba y bailaba a la vez (Pichardo, 1976: 68).

El punto utiliza un compás ternario $(3 / 4$ o 6/8). El modo más usado es el hipofrigio (sistema modal griego) y los ejecutantes le nombran mayor, el otro es una leve variante de la escala oriental andaluza nombrada como menor. La estructura conducente de los puntos es la homofónica en el punto libre y la heterofónica en los restantes estilos. La morfología es seccional o estrófica alternando solos instrumentales con partes cantadas con acompañamiento instrumental, presentándose en varias formas la división de estas secciones (Esquenazi, 2001: 72-73).

El mapa de música conga contiene los conjuntos instrumentales distribuidos por municipios de forma puntual, se señala también la existencia de cabildos donde se emplean estos conjuntos instrumentales y cuales tienen carácter histórico o vigente.

Los instrumentos y conjuntos instrumentales se encuentran vinculados mayormente, a grupos que practican los cultos del palo monte como: mayombe, kimbisa y briyumba, mientras otros se emplean en cabildos y sociedades de origen congo o bantú.

Los grupos étnicos bantú, conocidos como congos en Cuba, constituyeron el grueso de las dotaciones desde el inicio de la implantación de la esclavitud y estaban constituidos por grupos nombrados como: loango, musulongo, masinga, musundi, mucamba, musoro, olacamba, de Cabo Verde, bungana, morumbamba, mayaca, mironga, mondongo y los llamados congos reales (Deschamps, 1971: 34).
La mayoría de los cabildos congos rinden culto a San Antonio; casi siempre poseen un altar en la sala del cabildo, una piedra sagrada a la entrada del mismo, tinajas a Madre de Agua en el pozo del local y otras "prendas" en cuevas ocultas.

Los instrumentos musicales generalmente, poseen funciones rituales muy específicas como el garabato o lungowa, lo cual es una rama de árbol que se emplea para golpear la tierra $y$ despertar los poderes de la misma. La marímbula también tuvo sus funciones mágicas y actualmente, se emplea en la ejecución del son montuno, algo que ocurrió también con la tumbandera que consiste en un hoyo sobre el que coloca una hoja de yagua seca sujeta a la tierra, hacia su centro se coloca una cuerda que se tensa con un palo colocado fuera y la cuerda produce sonidos al ser tocada. Un instrumento similar se encuentra entre los haitianos que lo nombran caoline.

La kalunga es un gran tambor bimembranófono ejecutado por dos personas, quienes se suben encima de este. Estuvo oculto hasta los años 80 aproximadamente $y$ no le fue mostrado a Fernando Ortiz cuando visitó el Cabildo de congos reales de Trinidad.

El kinfuiti es un membranófono de fricción que se mantiene en uso en el cabildo congo de Quiebra Hacha, La Habana.

Los conjuntos más empleados son los tambores makuta y los yuka, los primeros son gruesos y los segundos más finos, ambos tipos de tambores son unimembranófonos.

La tendencia actual es la de sustituir estos conjuntos por tumbadoras (descendientes de las ngomas) y por cajones que se pueden conseguir y construir con más facilidad que los tambores antes mencionados (Esquenazi, 2001: 125-136).

En el mapa de música haitiana: migración del siglo xx, se señalan los conjuntos instrumentales de forma puntual y los municipios donde se encontraron.

Esta segunda migración masiva de los haitianos a Cuba se sitúa después de la Guerra de Independencia a inicios del siglo xx. Juan Pérez de la Riva calcula la permanencia en Cuba de aproximadamente 165000 haitianos 
hacia 1929 (Pérez de la Riva, 1979: 5). El Censo de población de 1970 (1975) arroja la cantidad de 17939 haitianos, los cuales 12926 tenían más de 65 años. En el presente, la mayoría son descendientes de haitianos y los nombran como "pichones".

Los conjuntos instrumentales se encuentran vinculados a diferentes cultos del vudú y a festividades sacras como la Semana Santa, así como, a la interpretación de música festiva bailable.

Entre los conjuntos que interpretan música ritual dahomé se emplea un conjunto de tambores unimembranófonos denominados (de mayor a menor tamaño) como dahomé, tambú radá o maman, el second leguedé y leguedé. Se emplea también una maraca para guiar el ritmo que posee un valor ritual, al representar a los dioses y una guataca como guía rítmica, esto coincide también en la música de antecedente africano.

Otro grupo instrumental es el nagó, los tambores se nombran bulá, coupé y gondé. Estos conjuntos de tambores son bien diferentes en su construcción a los anteriores. Los dahomé son semejantes a los tambores arará que se encuentran en Cuba, en cuanto a su tamaño $y$ forma de construcción, mientras que los nagó son más pequeños que los dahomé y los tres tienen el mismo tamaño. También se encuentra en algunos grupos, la sustitución de estos tambores por tumbadoras.

El bande rara es la fiesta de Semana Santa, en la cual realizan un recorrido que contiene varios rituales, se utiliza el caoline antes de la salida del grupo y se emplean el kesulat (redoblante) y varios idiófonos: un katá generalmente, hecho con una lata de aceite vacía que se cubre con yagua y se percute con palillos, el tambourin (pandereta de gran tamaño), trian o guataca ejecutado por el sambá o guía del canto, también se tocan los instrumentos de viento denominados vaccine (tubos de caña brava o caucho) y lambí (caracol).

La diversidad de cultos es bastante grande $y$ aunque son conocidos en general como vudú, son mucho más complejos de lo que parecen, pues varían según la zona de procedencia (norte o sur de Haití) y también con el área donde se desarrollan, observándose múltiples variantes regionales que no excluyen la asimilación de creencias cubanas como la santería.

La música bailable comprende los géneros del merengue, la polka, el mazún y el congó, estos dos últimos bailes también se interpretan en fiestas rituales, pero en estas los loas poseen a sus creyentes mientras que en las fiestas sociales como el Load Blanche de fin de año esto no ocurre. El conjunto instrumental debe ser bandoneón, flauta, violín, paila y tambourin, pero se acompaña con lo que se tenga a mano (Esquenazi, 2001: 166).

\section{3) APLICACIÓN PRÁCTICA DE LOS PARÁMETROS ESTABLECIDOS}

El análisis de la dinámica se realizó a nivel provincial en el caso del punto guajiro o cubano, por ser una manifestación muy extendida $y$ a nivel municipal, con la música de antecedente congo y la haitiana del siglo $\mathrm{xx}$, por ser más limitada geográficamente.

La cantidad de información compilada y procesada para la inclusión de la misma en los mapas, es extensa y su reproducción haría muy largo el presente artículo, pero tomando en consideración el carácter de propuesta metodológica de este trabajo, se pondrán ejemplos de las fichas confeccionadas con el resumen de los datos que se incluyen en los mapas de dinámica.

$\diamond \quad$ Fichas sobre punto guajiro con los informantes entrevistados en el municipio de Palmira, provincia de Cienfuegos, especificando si pertenece a una zona urbana o rural, su edad y si la transmisión es positiva o negativa.

\section{Ejemplo de ficha de informante}

Los números a la izquierda representan la clasificación por materia: el género del punto guajiro (11), el estilo cruzado con estribillo (07), el origen hispánico (18).

Los números a la derecha corresponden a la clasificación del lugar: Provincia de Cienfuegos (06), Municipio de Palmira (03), cabecera del municipio llamada también Palmira (001). 
I. Generales del informante
11.07 .18
06.03 .001

Nombre: Sierra Morales, Diego. Dirección: San Agustín no.150, Palmira, Cienfuegos.

Edad: 80 años. Estado civil: casado con nueve hijos. Piel Blanca. Escolaridad: $5^{\circ}$ grado. Ha vivido toda su vida en Palmira.

Informa sobre punto guajiro (Punto cruzado con estribillo)

Entrevistado por Consuelo Cabrera, el 10 de mayo de 1982.

Cuestionario de punto guajiro:

Provincia: Cienfuegos Municipio: Palmira Nombre $y$ apellidos del informante: Diego Sierra Morales

6.1. ¿Desde cuándo canta punto guajiro? Practica el género desde los 15 años.

6.2. ¿De quién lo aprendió? No lo aprendió de nadie (sic).

6.3. ¿Sus hijos u otros familiares o amigos lo han aprendido de ud. Explique.

Dos de sus hijos tocan guitarra mientras otro canta.

6.4 ¿Participa en algún tipo de reunión para cantar tonadas e improvisar? ¿Cómo le llaman? Participaba en los guateques.

6.5 ¿Dónde se realizan o realizaban estas reuniones $y$ de qué lugares proceden o procedían los participantes? Estas fiestas se celebraban en las casas.

6.6 ¿Qué tipo de punto interpreta?

libre (sin estribillo)

libre (con estribillo)_

fijo (sin estribillo)

fijo (con estribillo)

cruzado (sin estribillo)

cruzado (con estribillo) $\underline{X}$

Espirituano (con estribillo coreado) Seguidilla__ Parranda___ Otros:

6.7 ¿Improvisa? ¿Qué tonada utiliza para improvisar? Lo interpretaba con distintas tonadas [fórmulas melódicas con las que se interpretan las décimas].
6.8 ¿Se acompaña con algún grupo instrumental? Diga cómo está compuesto.

Se acompañaba con una guitarra, menciona a Donato Leal ( $\dagger$ y Pancho Sarria (cantante).

6.9 ¿Se acompaña usted mismo? No

6.10 Anote algunas de las décimas que utiliza con sus estribillos en caso de que los lleven algunas de las tonadas que interpreta.

Tuve un tiempo en que podía/ y era mi canto expresivo

cuando por cualquier motivo/ inspirado me sentía y la dulce lira mía/ casi nunca destemplaba y cada vez que llegaba/ a mi querido bohío a mi patria con sonrisas/ mis arrullos le brindaba.

En este caso, el informante se ubica como perteneciente a una zona urbana (el pueblo de Palmira, cabecera del municipio), se coloca en la categoría de más de 61 años y su transmisión es positiva.

Los datos compilados sobre punto guajiro en este municipio de Palmira se resumirán tomando en consideración estos datos en particular:

1. Castellanos T., Urbicio. San Fernando de Camarones, zona urbana del municipio Palmira, entre 31 a 60 años, transmisión negativa.

2. Colarte Noa, José. Zona urbana de Palmira, entre 31 a 60 años, transmisión negativa.

3. Dueñas Valdés, Luis. Zona urbana de Palmira, entre 31 a 60 años, transmisión negativa.

4. Figueredo, Luis. Zona urbana de Palmira, entre 31 a 60 años, transmisión negativa.

5. Hernández Castillo, José. Zona urbana de Palmira, más de 61 años, transmisión positiva.

6. López Arencibia, Juan. Zona urbana de Palmira, entre 31 a 60 años, transmisión negativa.

7. Macías Villazón, Mariano. Finca Jurisdicción, zona rural, más de 61 años, transmisión positiva. 
8. Martínez Muñoz, Máximo. Cerice nro. 2, zona rural de Palmira, más de 61 años, transmisión negativa.

9. Medina, Cándida. Zona urbana de Palmira, más de 61 años, transmisión negativa.

10. Morales Martínez, Berto. Cooperativa agrícola de Ciego Montero, zona rural de Palmira, entre 31 a 60 años, transmisión negativa.

11. Otero Vázquez, Francisco. Zona urbana de Palmira, entre 31 a 60 años, transmisión positiva.

12. Pérez Valencia, Francisco. Zona urbana de Palmira, más de 61 años, transmisión positiva.

13. Puerto, José Isaac. Zona urbana de Palmira, más de 61 años, transmisión negativa.

14. Rodríguez, Juan Andrés. Manaquita, San Fernando de Camarones, Palmira (Zona rural), entre 31 a 60 años, transmisión positiva.

15. Santana, Zenén. Zona urbana de Palmira, entre 31 a 60 años, transmisión negativa.

16. Sierra Morales, Diego. Zona urbana de Palmira, más de 61 años, transmisión positiva.

17. Vega Falcón, Alberto. Zona urbana de Palmira, entre 31 a 60 años, transmisión negativa.

18. Vega, Ramón. Zona urbana de Palmira, no aparece la edad, transmisión negativa.

19. Vizcaíno Ruiz, Alejandro. Zona urbana de Palmira, más de 61 años, transmisión positiva.

En resumen, aparecen:

$\diamond \quad 15$ informantes de zona urbana y 4 de zona rural

$\diamond \quad$ Ningún informante hasta 30 años

$\diamond \quad 10$ informantes de 31 a 60 años

$\diamond \quad 8$ informantes de más de 61 años

$\diamond \quad 1$ informante que no dijo la edad

$\diamond \quad 7$ informantes cuya transmisión es positiva (3 de ellos de zona rural)

$\diamond \quad 12$ informantes cuya transmisión es negativa (1 de ellos de zona rural)
Predominan los informantes entrevistados en zonas urbanas, los de 31 a 60 años y la transmisión negativa.

A estos resultados se suman los de los demás municipios de la provincia, con la finalidad de determinar su forma de representación a nivel provincial. Se puede apreciar que esta representación no excluye la existencia de otras variables, sino que toma las que resultan preponderantes de acuerdo al total que se encontró durante la investigación de campo.

La metódica descrita se repitió con la música de antecedente congo y la de procedencia haitiana, en el caso de estos tipos de música se aplicó la parte del cuestionario dedicada a "Otro tipo de cantos tradicionales".

Ejemplo de una ficha de informante: música de antecedente congo o bantú aplicada en el municipio de Nueva Paz, actual provincia Mayabeque:

Nombre y apellidos: Tarafa, Ángel. Dirección: Cuervo no. 1500. Nueva Paz, provincia Habana (zona urbana). Edad: 63 años.

Estado civil: casado. Número de hijos: siete hijas.

Escolaridad: primaria. Color de la piel: negra. Ocupación habitual: no dice.

¿Qué tiempo hace que reside en el lugar donde vive actualmente?

Nació en Nueva Paz y ahí ha pasado toda su vida.

¿Sobre qué aspectos de la música popular tradicional puede brindarnos información?

Informa sobre "otro tipo de cantos tradicionales": cantos congos.

Nombre $y$ apellidos del compañero que recoge la información: Jorge González.

Fecha en que fue realizada la entrevista: 17 de septiembre de 1981.

Observaciones: no tiene.

Ejemplo del cuestionario de "Otro tipo de cantos tradicionales".

Clasificación de lugar: 02.11.001

Clasificación de materia: 09.03.05

Manifestación vigente

Histórica $\underline{X}$ 
Provincia: La Habana. Municipio: Nueva Paz. Nombre $y$ apellidos del informante: Ángel Tarafa.

10.1 ¿Qué tipo de cantos tradicionales conoce?: Cantos de origen congo.

10.2 ¿En qué forma participaba o participa usted en la interpretación de estos géneros? Cantando__ Tocando un instrumento_-_ Oyendo $\underline{X}$ Otros__ Amplíe

10.3 ¿Perteneció o está vinculado a un grupo étnico determinado? ¿Cuál? (En caso de pertenecer a un Cabildo, Sociedad o Peña determinada, anexar una breve reseña histórica de la institución). Sin respuesta.

10.4 ¿Se reúnen para cantar? ¿Dónde? (decir de dónde proceden los participantes y si se desplazan a otros lugares, menciónelos).

Aquí en Nueva Paz, en el Cabildo Africano de la Virgen de Regla. En este participaban los congos que había en el municipio (según el informante ya no existe).

10.5 ¿Se reúnen en alguna fecha determinada o con alguna frecuencia establecida?

Se reunían el 8 de septiembre $y$ los fines de semana.

10.6 ¿Desde cuándo conoce estos cantos? Desde niño.

10.7 ¿De quién los aprendió? De oírlos en el Cabildo.

10.8 ¿Sus hijos, familiares o amigos lo han aprendido o lo aprenden de ud.? En caso negativo explique el motivo: Ya no se practican.

10.9 Se canta con:

Solista Coro Ambos $\underline{X}$ Otros

10.10 ¿Se canta con acompañamiento? ¿Con qué tipo de conjunto? ¿Se acompaña usted mismo? Diga los instrumentos que lo componen.

Tambores: un golpe, dos golpes, la caja $y$ el medio, los palitos (guaguas) que se tocan sobre el tambor dos golpes; el de la caja se ponía dos güiritos en las muñecas.

[Tambores makuta]
10.11 En caso de que estos cantos y toques tengan un orden ritual, anexe si es posible, una descripción de dicho orden: no tienen orden ritual.

10.12 Textos de los cantos

Textos de cantos de makuta grabados en Cassette 202.

Resumen de los datos de los informantes que conocían sobre la música de antecedente congo en Nueva Paz, Mayabeque:

1. Brindis Gómez, Moisés. Zona urbana de Nueva Paz, más de 61 años, transmisión negativa.

2. Padilla Vigil, Pablo. Zona urbana de Nueva Paz, más de 61 años, transmisión negativa.

3. Tarafa, Ángel. Zona urbana de Nueva Paz, más de 61 años, transmisión negativa.

4. Tarafa, Rogelio. Zona urbana de Nueva Paz, más de 61 años, transmisión positiva.

En resumen, aparecen:

$\diamond \quad 4$ informantes de zona urbana

$\diamond \quad$ Ningún informante hasta 30 años

$\diamond \quad$ Ninguno de 31 a 60 años

$\diamond \quad 4$ informantes de más de 61 años

$\diamond \quad 1$ informante con transmisión positiva

$\diamond \quad 3$ informantes cuya transmisión es negativa

Predominan los informantes entrevistados en zonas urbanas, los de más de 61 años y la transmisión negativa.

Esta valoración es la que aparece en este municipio, aunque el cabildo ya no funciona $y$ todo parece indicar que la manifestación desapareció, puede que sobrevivan las creencias religiosas en alguna modalidad.

Ejemplo de dinámica de la transmisión oral: música haitiana en el municipio Esmeralda de Camagüey.

Música haitiana, dinámica

Ejemplo de ficha de informante $y$ de ficha cuestionario de un informante del municipio escogido.

Municipio seleccionado: Esmeralda, Camagüey 
I. Generales del informante

1.1 Nombre y apellidos: Otilio Simón

Dirección: José E. Varona no.42. Esmeralda, Camagüey.

Zona rural___ Zona urbana $\underline{\mathrm{X}}$

Edad: 47 años. Estado civil: soltero. Número de hijos: tres hijos

Escolaridad: segundo grado de primaria.

Color de la piel: piel negra

Ocupación habitual: obrero agrícola

Lugar de nacimiento: Haití

Lugares donde ha residido: Haití y

Esmeralda

¿Qué tiempo hace que reside en el lugar donde vive actualmente?

Vive en Esmeralda desde 1957.

¿Sobre qué aspectos de la música popular tradicional puede brindarnos información?

Informa sobre cantos de cuna e infantiles, otro tipo de cantos tradicionales y construcción de instrumentos.

Nombre y apellidos del compañero que recoge la información y realiza las entrevistas: Rafael García Grasa.

Fechas en que fueron realizadas las entrevistas: no dice.

Observaciones: no tiene

Clasificación de lugar: 09.02.001 Clasificación de materia: 10.04.07 Manifestación vigente $\underline{X}$ Histórica

Otro tipo de cantos tradicionales

Provincia: Camagüey

Municipio: Esmeralda

Nombre $y$ apellidos del informante: Otilio Simón

10.1 ¿Qué tipo de cantos tradicionales conoce?: haitianos

10.2 ¿En qué forma participaba o participa usted en la interpretación de estos géneros?

Cantando $\underline{\mathrm{X}}$ Tocando un instrumento $\underline{\mathrm{X}}$ Oyendo Otros Amplíe

10.3 ¿Perteneció o está vinculado a un grupo étnico determinado? ¿Cuál? (en caso de pertenecer a un Cabildo, Sociedad o Peña determinada anexar una breve reseña histórica de la institución).

Haitiano. Es director de folclor haitiano de aficionado "Dešami" (Deux ami: Dos amigos).

10.4 ¿Se reúnen para cantar? ¿Dónde? (decir de dónde proceden los participantes y si se desplazan a otros lugares, menciónelos).

En el círculo social "Macantalla", en fiestas haitianas, en casas particulares de la zona de Maragabomba, Mamanantuabo, Brasil, etc.

10.5 ¿Se reúnen en alguna fecha determinada o con alguna frecuencia establecida?

El grupo de aficionados ensaya por la noche, pero también participa en las fiestas que se producen en el Municipio.

10.6 ¿Desde cuándo conoce estos cantos? Desde 1944 o 1945.

10.7 ¿De quién los aprendió? De mi familia $y$ amigos

10.8 ¿Sus hijos, familiares o amigos lo han aprendido o lo aprenden de ud.? En caso negativo explique el motivo.

Un hijo y amigos.

10.9 Se canta con: solista coro ambos $\underline{X}$ otros

10.10 ¿Se canta con acompañamiento? ¿Con qué tipo de conjunto? ¿Se acompaña usted mismo? Diga los instrumentos que lo componen (si existen varios tipos de conjuntos para diversas festividades rituales, especifíquelo.

Tambores dahomé (gadá), tambourins, caolina, sambá.

10.11 En caso de que estos cantos y toques tengan un orden ritual, anexe si es posible, una descripción de dicho orden.

Tres rezos a Legbá y los cantos al loa de la fiesta (Přvieye) (rezo) en caso de Loa (deidad). El gagá tiene un (aprï̈e) apertura $y$ luego el recorrido.

10.12 Textos de los cantos.

Grabados en el casette 01 .

Resumen de los datos de los informantes que conocían sobre la música de antecedente haitiano en Esmeralda, Camagüey: 
1. Flores, Alberto. Zona urbana de Esmeralda, entre 31 a 60 años, transmisión positiva.

2. Ruiz Solaris, José Rafael. Zona urbana de Esmeralda, entre 31 a 60 años, transmisión negativa.

3. Simón, Otilio. Zona urbana de Esmeralda, entre 31 a 60 años, transmisión positiva.

En resumen aparecen:

$\diamond \quad 3$ informantes de zona urbana

$\diamond \quad$ Ningún informante hasta 30 años

$\diamond \quad$ Tres informantes de 31 a 60 años

$\diamond \quad$ Ningún informante de más de 61 años

$\diamond \quad 2$ informantes con transmisión positiva

$\diamond \quad 1$ informante cuya transmisión es negativa

En resumen, predominan los informantes de 31 a 60 años, la zona urbana y la transmisión positiva.

En el trabajo de campo realizado en 1989, se entrevistó en Esmeralda, las siguientes personas: Filiberto Flores y Alberto Flores (edades de 31 a 60 años, transmisión positiva y zona urbana también), también se grabaron y fotografiaron los músicos del grupo Belles fleurs que interpretaron un toque de Bande rara $y$ otro a Ibo (culto especial) con un grupo de instrumentos que combinaban los tambores dahomé e idiófonos construidos con materiales diversos que sustituían al katá, la maraca y el tambourin más una guataca (Esquenazi, 1991: 87, 90 y 92 ).

\section{BIBLIOGRAFÍA}

De Freitas Mendonça, Paulo. Payadores del Brasil. Estudio sobre la poesía oral improvisada. Porto Alegre: Editora Evangraf Ltda., 2009.

Deschamps Chapeaux, Pedro. El negro en la economía habanera del siglo XIX. La Habana: Ediciones Unión, 1971.

Eli Rodríguez, Victoria et ál. Atlas de los instrumentos de la música folclóricopopular de Cuba. Cuba: Ediciones GEo y Centro de Investigación y Desarrollo de la Música Cubana, 1996.
Esquenazi Pérez, Martha Esther. "Apuntes para un estudio de la música haitiana en Camagüey". Anuario de Etnología de 1989. La Habana. Editorial Academia, 1991: 75-96.

Esquenazi Pérez, Martha Esther. "Sección de música". Atlas etnográfico de Cuba. CD publicado por el ceisic $y$ otras entidades. Bogotá, 2000.

Esquenazi Pérez, Martha Esther. Del areito y otros sones. La Habana: Editora Letras Cubanas, 2001.

Esquenazi Pérez, Martha Esther. "La décima cantada en América Latina". Revista Clave 1-2 (10). Ciudad Habana. Segunda época, 2008: 64-75.

García Grasa, Rafael. "Apuntes sobre elementos de las danzas haitianas en la provincia de Camagüey”. Material mimeografiado. Sin fecha.

González, Juan F. El Cabildo congo de Nueva Paz. Inédito. Sin fecha. (Archivo de música del Atlas etnográfico de Cuba).

López Lemus, Virgilio. "La décima renacentista y barroca". La Habana: Editorial Pablo de la Torriente Bravo, 2002.

Moreno Chá, Ercilia. "La música del payador de Argentina y Uruguay". Actas del VI Encuentro-Festival Iberoamericano de la décima y el verso improvisado. Madrid. Universidad de Las Palmas, 2000: 291-296.

Pérez de la Riva, Juan. "La república neocolonial". Anuario de estudios cubanos. Tomo II. La Habana: Instituto Cubano del Libro, 1979.

Pichardo, Esteban. Diccionario provincial y casi razonado de voces y frases cubanas. La Habana: Editorial de Ciencias Sociales, 1976.

República de Cuba, Junta Central de Planificación. Censo de población y viviendas, 1970. La Habana: Editorial Orbe, 1975.

Trapero, Maximiano. "Vicente Espinel, la décima espinela y lo que de ellos dicen los decimistas". Actas del VI EncuentroFestival Iberoamericano de la décima y el verso improvisado. Madrid. Universidad de Las Palmas, 2000: 117-140. 
ANEXOS 



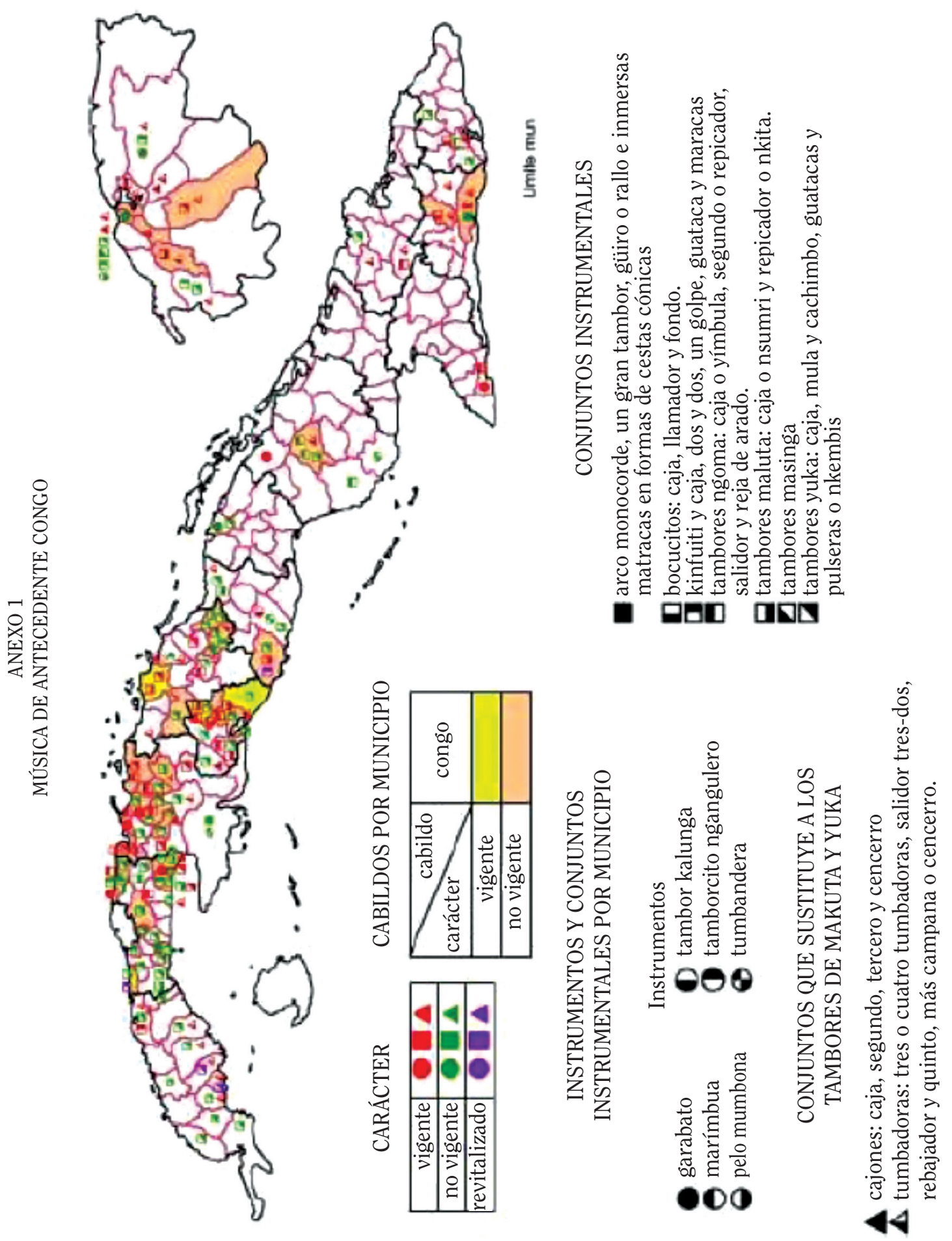




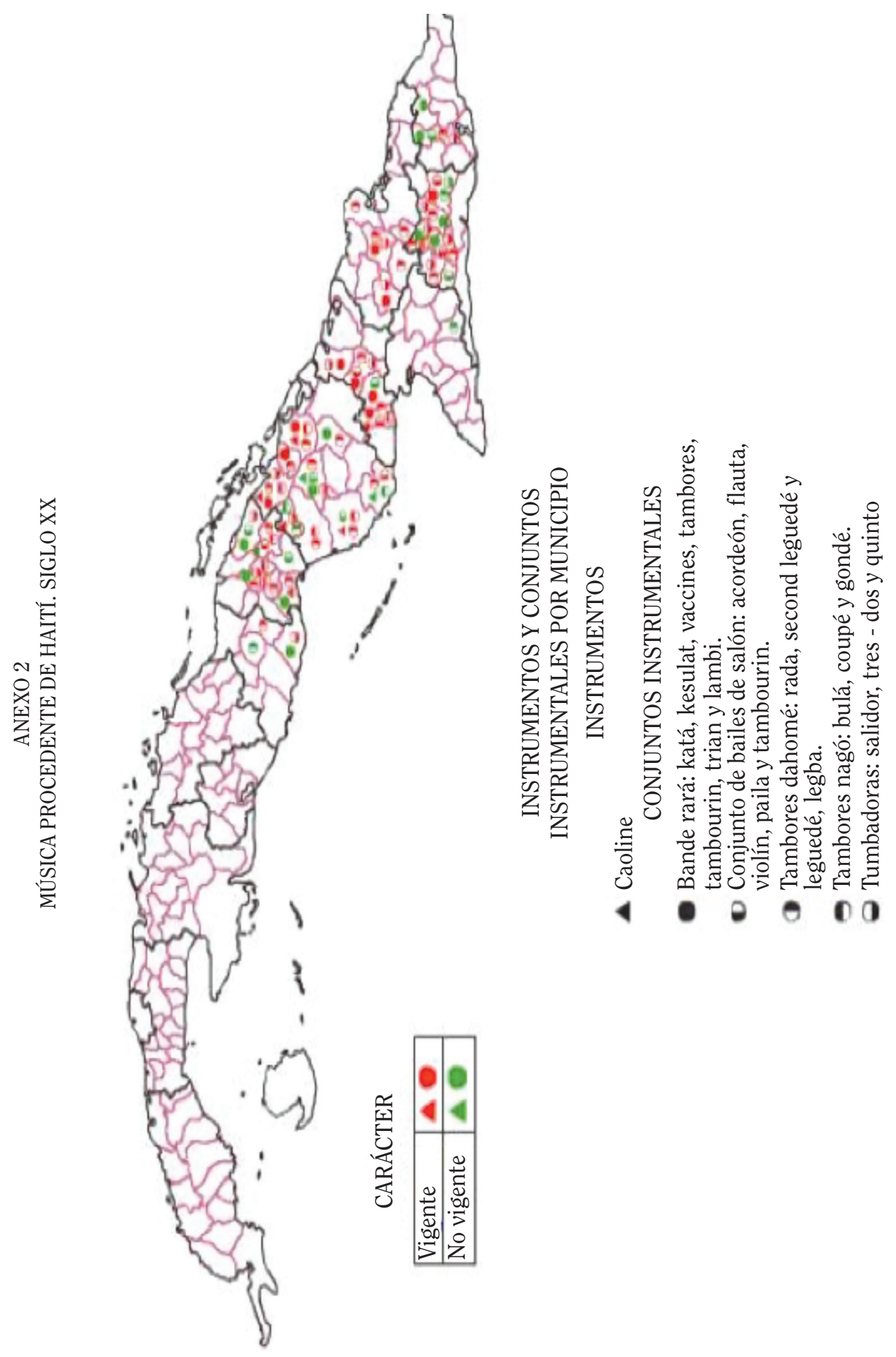



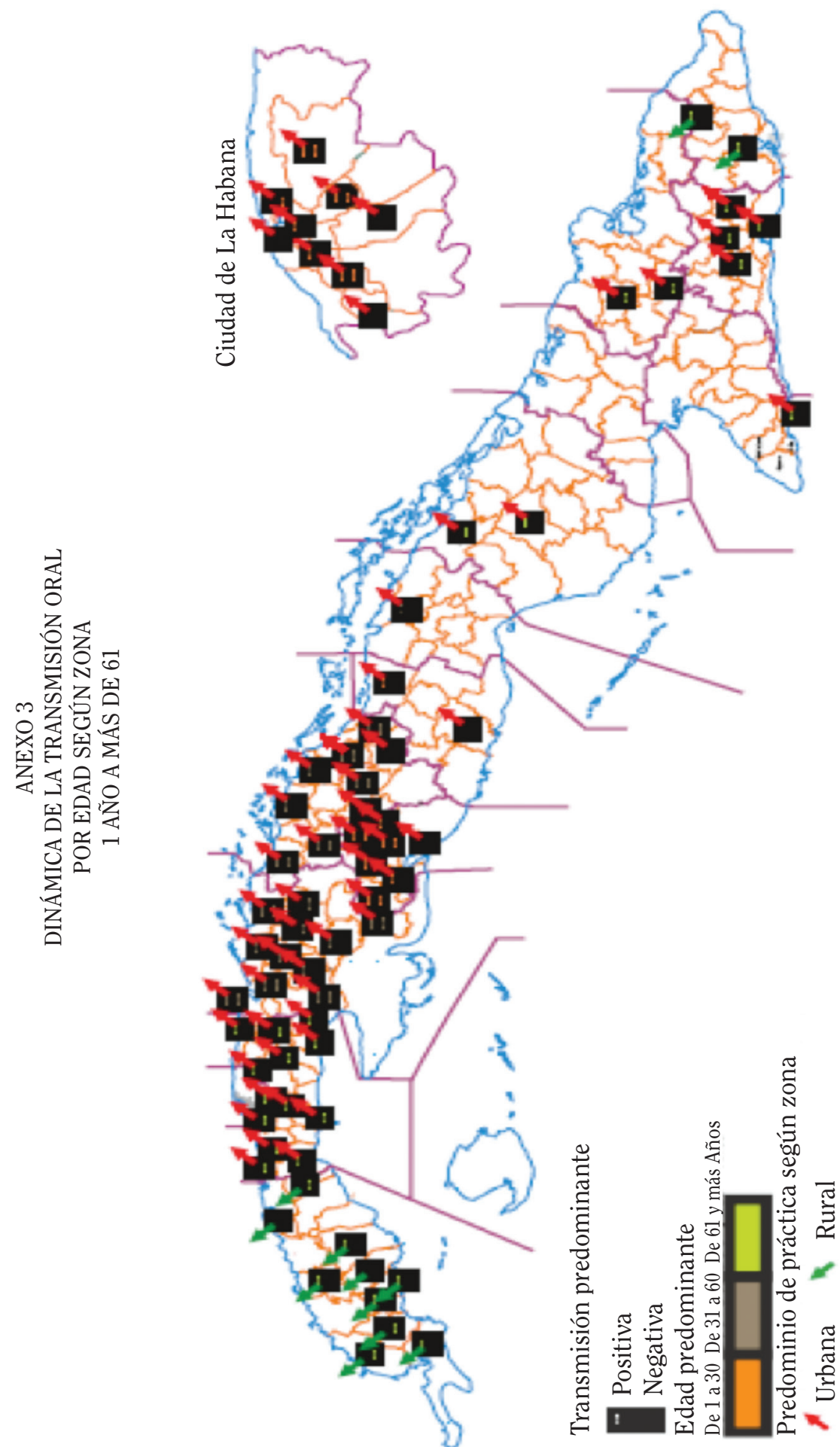

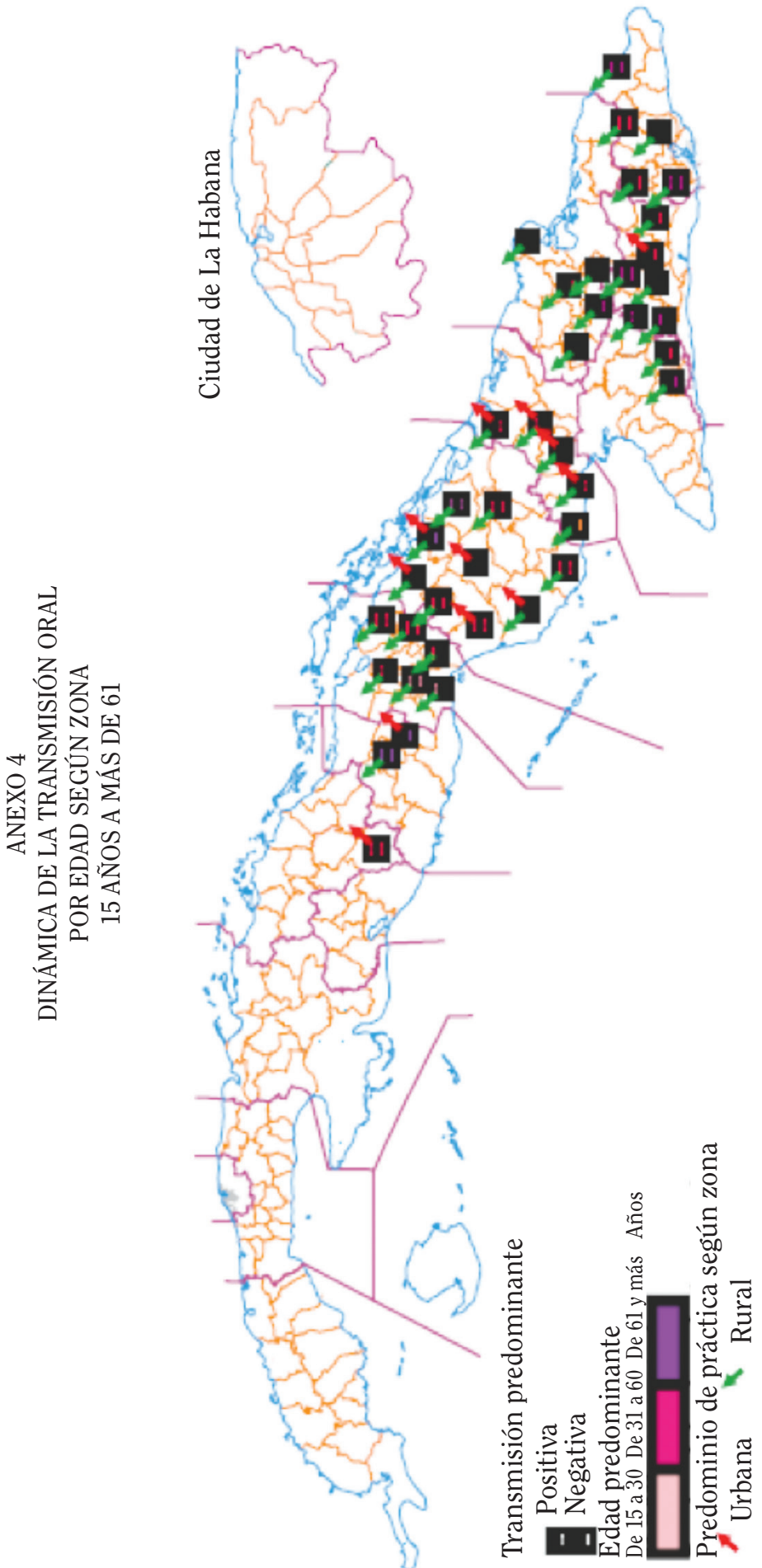

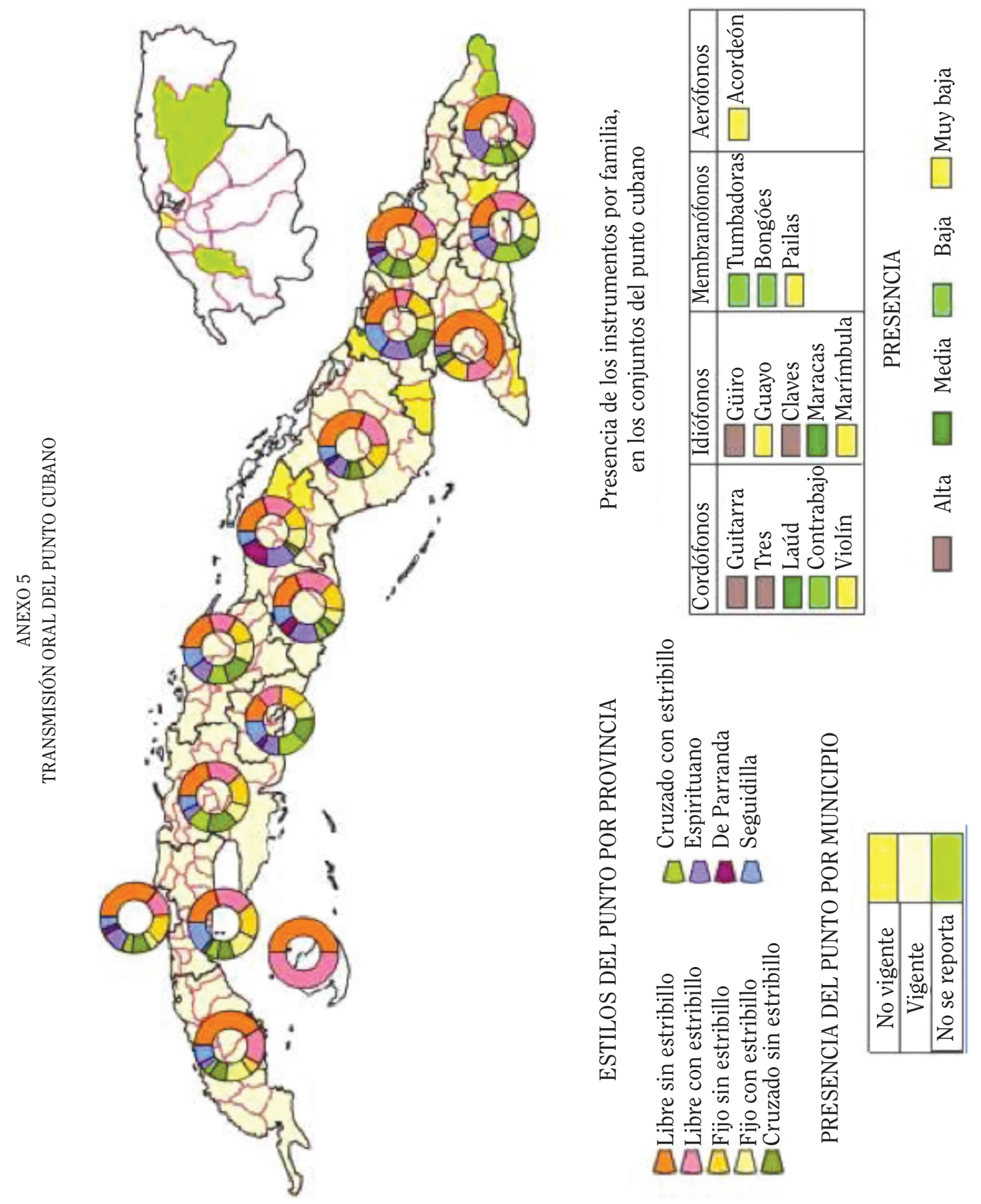

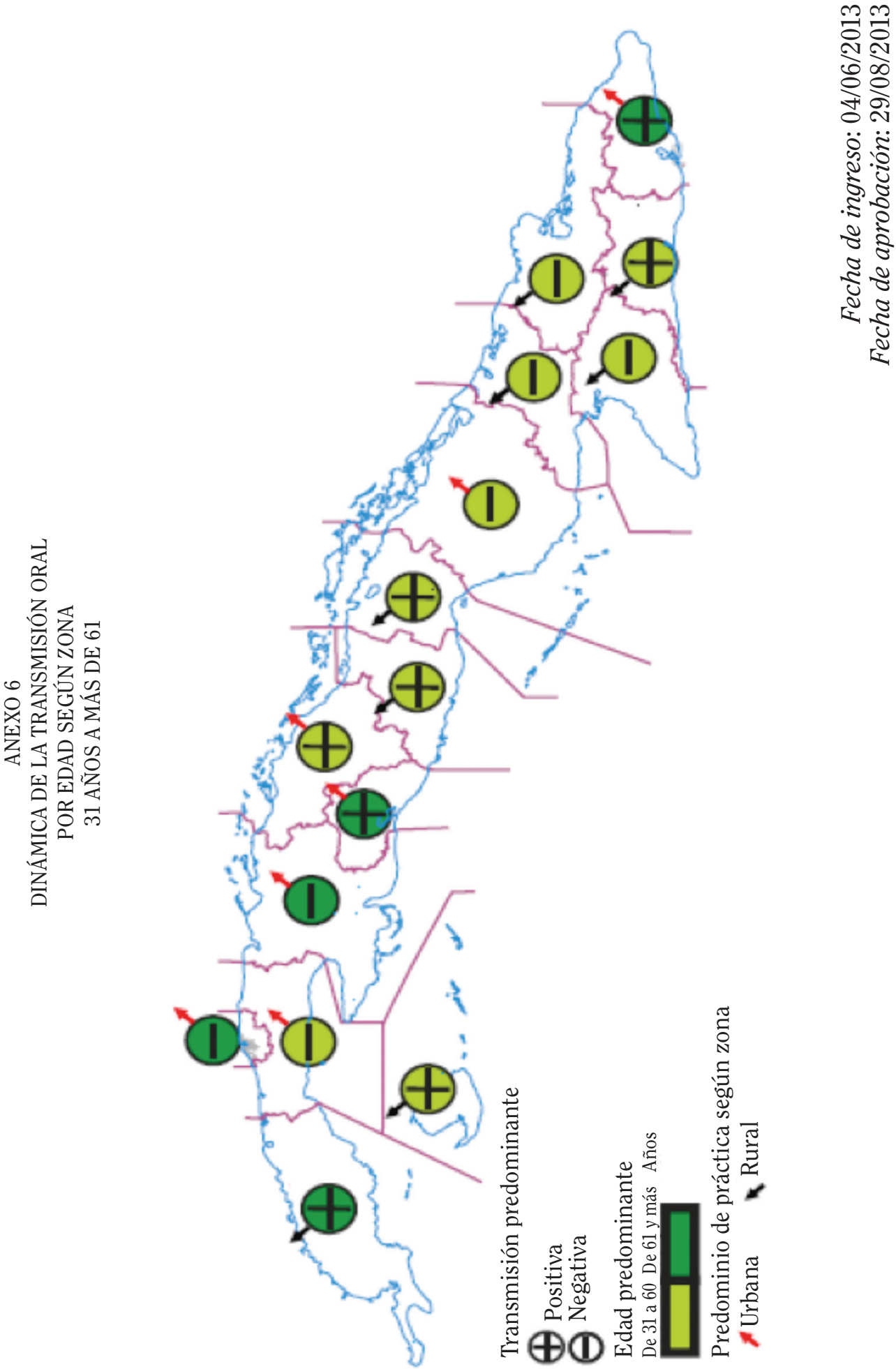